\title{
Kuolemantapaukset perusterveydenhuollon lyhytaikaisessa sairaalahoidossa
}

\author{
Alisa Piikki ${ }^{1}$, Henna Saari ${ }^{1,2}$, Eija Lönnroos $^{1}$ \\ ${ }^{1}$ Kansanterveystieteen ja kliinisen ravitsemustieteen yksikkö, Lääketieteen laitos, Itä-Suomen yliopisto \\ ${ }^{2}$ Perusterveydenhuollon yksikkö, Pohjois-Savon sairaanhoitopiiri
}

\begin{abstract}
Maassamme kuolee yli 50000 henkilöä vuosittain. Merkittävä osuus suomalaisista kuolee perusterveydenhuollon (PTH) sairaaloissa; silti tutkimusta aiheesta on tehty verrattain vähän. Tässä tutkimuksessa kuvataan PTH-sairaaloissa kuolemaan päättyneiden hoitojaksojen piirteitä Kuopion yliopistollisen sairaalan erityisvastuualueella (KYS erva-alue). Tutkimukseen osallistuivat kaikki KYS erva-alueen PTH-sairaalat. Tiedonkeruu toteutettiin strukturoitua tiedonkeruulomaketta käyttäen vuoden 2016 tammi-kesäkuussa. Tarkastelu rajattiin enintään 31 vuorokautta kestäneisiin hoitojaksoihin. PTH-sairaaloiden lyhytaikaisista hoitojaksoista ( $\mathrm{n}=13869) 4$ prosenttia $(\mathrm{n}=625)$ päättyi potilaan kuolemaan. Kuolemaan päättyneistä hoitojaksoista 46 prosentissa hoidon pääasialliseksi syyksi oli määritelty elämän loppuvaiheen hoito. Sydän- ja verenkiertoelimistön sairaudet (29\%) sekä syöpäsairaudet $(30 \%)$ olivat yleisimmät päädiagnoosit kuolemaan päättyneillä hoitojaksoilla. Hoito PTH-sairaalassa kesti keskimärin 8,6 vuorokautta, mutta 20 prosentilla potilaista vain vuorokauden tai kaksi. Kuoleman läheisyyttä ei ollut tiedostettu yli puolessa PTH-sairaaloiden hoitojaksoista, jotka päättyivät potilaan kuolemaan. Lisäksi neljäsosa potilaista oli PTH-sairaalassa enintään kaksi vuorokautta ennen kuolemaansa. Pohdittavaksi jää, olisiko näiden potilaiden hoitoa voitu toteuttaa toisin.
\end{abstract}

\section{Johdanto}

Suomessa toimii kattava perusterveydenhuollon (PTH) sairaaloiden verkosto. PTH-sairaalahoito on yleisimmin yleislääkärijohtoista, ja sitä toteutetaan terveyskeskusten lisäksi keskussairaaloiden yleislääketieteen osastoilla (Mikkola ym. 2015). Hoidossa keskeisintä on iäkkäiden ihmisten akuuttien sairauksien hoi-

taminen ja pitkäaikaissairauksien pahenemisvaiheiden hoito (Saari ym. 2019). Hoitojaksot ovat lyhentyneet oleellisesti kotihoidon ja asumispalvelujen kehittymisen myötä samalla kun terveyskeskussairaaloiden rooli on muuttunut pitkäaikaishoidosta akuuttihoidon suuntaan (Blomgren \& Einiö 2015; Saukkonen \& Vaurio 2017; Forma ym. 2018; Saari ym. 2019). 
PTH-sairaaloiden tehtäviin kuuluu myös elämän loppuvaiheen hoito, hyvän palliatiivisen ja saattohoidon tarjoaminen (Saarto 2017). Suomessa kuolee vuosittain noin 53000 henkilöä,ja heistä yli 60 prosenttia on yli 75-vuotiaita. Yleisimmät kuolinsyyt ovat sydän- ja verenkiertoelimistön sairaudet, syöpäsairaudet sekä muistisairaudet (Tilastokeskus 2018a). PTHsairaalahoidon käyttö lisääntyy kuolemaa edeltävänä vuotena perussairauksien romahduttaessa potilaan toimintakykyä. Lähes puolella yli 70-vuotiaista viimeinen hoitopaikka ennen kuolemaa on PTH-sairaala (Forma ym. 2012; Forma ym. 2018).

Iäkkäistä suomalaisista useimmat kuolevat terveydenhuollon yksiköissä. Yli 70 vuotta täyttäneistä 48 prosenttia kuoli terveyskeskuksissa, 19 prosenttia keskussairaalassa ja 6 prosenttia yliopistosairaaloissa. Noin neljännes kuoli kodinomaisessa ympäristössä, kotona (16 \%) tai palveluasumisen yksikössä (10 \%) (Aaltonen ym. 2010; Forma ym. 2012). PTHsairaaloissa kuolleista noin puolet oli viettänyt yksikössä 2-3 viikon mittaisen hoitojakson ennen kuolemaansa (Forma ym. 2012). Kuolevia potilaita saatetaan kuitenkin siirtää yksiköstä toiseen aivan viime hetkillä hoidonporrastukseen ja palvelujärjestelmän työnjakoon vedoten (Saarivaara ym. 2018).

Keskimäärin noin neljännes yksilön elinaikanaan käyttämien terveydenhuoltopalveluiden kustannuksista muodostuu viimeisenä elinvuotena. Kustannusten kasvu nähdään etenkin tilanteissa, joissa potilaalla ei ole ennakoivaa hoitosuunnitelmaa ja hän hakeutuu toistuvasti päivystykseen ja sairaalahoitoon pahenevien oireiden vuoksi. Kustannuksia ja potilaalle aiheutuvaa huolta ja turvattomuutta voitaisiin vähentää ennakoivalla hoidon suunnittelulla ja reagoimalla potilaan heikkenevään kuntoon varhaisessa vaiheessa (Saarto 2017).

Useimmissa tapauksissa kuoleman aiheuttaa sairaus, jonka kulkuun ei voida enää lääketieteellisin keinoin vaikuttaa. Kuolevan potilaan hoidon kulmakivinä ovat oikea diagnoosi, ensisijaisesti oireiden lievittämiseen tähtäävä hyvä hoito sekä potilaan ja hänen läheistensä tukeminen (Tilvis ym. 2016). Potilaan toimintakyvyn kehitys vaihtelee eri sairauksissa, mikä voi hankaloittaa elämän loppuvaiheen tunnistamista. Esimerkiksi sydämen vajaatoiminnassa merkittävästäkin toimintakyvyn laskusta on mahdollista toipua, kun taas muistisairaudessa toimintakyky yleensä heikkenee progressiivisesti (Lunney ym. 2002; Käypä hoito -suositus/Sydämen vajaatoiminta 2017). Merkityksellistä on tunnistaa ja ennen kaikkea tunnustaa lähestyvä kuolema, jotta hoitoa voidaan ohjata oikein (Käypä hoito -suositus/Palliatiivinen hoito ja saattohoito 2018).

Hoitojaksot PTH-sairaaloissa ja myös kuolema siellä ovat iäkkäille suomalaisille verrattain yleisiä.Tästä huolimatta PTH-sairaaloissa tapahtuneita kuolemia on tutkittu vähän. Tämän tutkimuksen tavoitteena oli kuvata Kuopion yliopistollisen sairaalan erityisvastuualueen (KYS erva) PTH-sairaaloiden lyhytaikaiset hoitojaksot, jotka päättyivät potilaan kuolemaan. Tutkimuksessa selvitettiin potilaiden päädiagnoosit kuolemaan päättyneiltä hoitojaksoilta, mistä potilaat saapuivat PTHsairaalaan, sekä kuinka usein kuoleman läheisyys oli tiedostettu. Lisäksi tutkittiin kerätystä aineistosta niitä hoitojaksoja, jotka eivät päättyneet potilaan kuolemaan, sekä käytettiin vertailutietona KYS erva-alueella vuonna 2016 tapahtuneita kaikkia kuolemia.

\section{Aineisto ja menetelmät}

Tutkimus toteutettiin KYS erva-alueen kaikissa PTH-sairaaloissa. Maantieteellisesti alue kattaa Pohjois-Savon, Etelä-Savon, Itä-Savon, Keski-Suomen sekä Pohjois-Karjalan sairaanhoitopiirit. Erva-alueen väestöpohja on noin 813000 henkilöä. Tutkimukseen osallistui 65 perusterveydenhuollon ja 2 erikoissairaanhoidon yleislääketieteen osastoa. PTHsairaaloiden osastoilla oli yhteensä 1934 potilaspaikkaa. Aineisto kerättiin strukturoidulla lomakkeella vuoden 2016 tammi-kesäkuun ai- 
kana. Tutkimuksessa huomioitiin kaikki enintään 31 vuorokautta kestäneet PTH-sairaaloiden hoitojaksot; tähän vuorokausirajaukseen päädyttiin esitutkimuksen perusteella (Saari ym. 2019). Aineistonkeruu on kuvattu yksityiskohtaisemmin edellä mainitussa aiemmassa julkaisussa. Lisäksi alkuperäinen tiedonkeruulomake on luettavissa verkkolehdessä sähköisenä liitetiedostona. Tämä tutkimus on osa laajempaa perusterveydenhuollon lyhytaikaisen sairaalahoidon tutkimusprojektia. PohjoisSavon sairaanhoitopiirin tutkimuseettinen toimikunta on arvioinut tutkimussuunnitelman ja antanut puoltavan lausunnon.

PTH-sairaaloiden hoitavat lääkärit, osastonsihteerit ja kuntoutuksen ammattilaiset täyttivät tutkimuksen sähköisen tiedonkeruulomakkeen hoitojaksojen päättyessä (Saari ym. 2019). Tutkimus ei aiheuttanut potilaille toimenpiteitä. Tiedonkeruulomakkeessa kysyttiin, mistä potilaat saapuivat PTH-sairaalaan, mitkä olivat heidän pää- ja sivudiagnoosinsa sekä minne ja millaisten palveluiden piiriin potilaat uloskirjoitettiin PTH-sairaalasta, jolloin kuolema oli yksi valittavista vaihtoehdoista. Diagnoosien lisäksi kysyttiin myös hoidonsisällöstä, ja jos hoidonsisällöksi oli valittu saattohoito tai elämänkaaren loppuvaiheen hoito, katsottiin, että kuoleman läheisyys oli tiedostettu. Tiedonkeruulomakkeet eivät sisältäneet suoria henkilötunnisteita, kuten potilaan nimeä tai henkilötunnusta. Valmiista tutkimuksesta ei voi tunnistaa yksittäistä hoitojaksoa.

Tilastokeskuksen avoimesta arkistotietokannasta haettiin tiedot KYS erva-alueen väestön kuolemista ja kuolemansyistä vuodelta 2016 (Tilastokeskus 2018b). KYS erva-alueen kuolemat haluttiin esittää kokonaiskuvana alueen väestön kuolleisuudesta. Tutkimuksessa kuvataan myös tutkimusalueen perusterveydenhuollon lyhytaikaisen sairaalahoidon kuolemaan päättymättömät hoitojaksot, jotta syntyy kuva siitä, millaisesta joukosta tutkittu osajoukko on poimittu.

Aineiston kuvaamiseen on käytetty frekvenssi- ja prosenttijakaumia, keskiarvoja, me- diaaneja, keskihajontaa (SD), vaihteluväliä ja 95 \%:n luottamusväliä. Tilastolliset analyysit tehtiin SPSS-ohjelman versiolla 24.0.

\section{Tulokset}

Aineisto sisälsi tiedot 13869 enintään 31 vuorokautta kestäneestä hoitojaksosta KYS ervaalueen PTH-sairaaloissa. Potilaista naisia oli 54 prosenttia $(n=7461)$. Potilaiden keski-ikä oli 76 (SD 13,8) vuotta. Suurin ikäryhmä olivat yli 84 -vuotiaat (34\%). Alle 65-vuotiaita oli 16 prosenttia potilaista. Hoitojaksoista 625 (4\%) päättyi potilaan kuolemaan (taulukko 1). Kuolleista 49 prosenttia $(n=302)$ oli naisia. Kuolleiden henkilöiden keski-ikä oli 80 (SD $10,8)$ vuotta, naisten 83 (SD 9,9) ja miesten 78 (SD 11,2) vuotta, ja enemmistö (76 \%) oli 75 vuotta täyttäneitä. Kaikista aineiston hoitojaksoista 361 oli määritelty elämän loppuvaiheen hoidoksi tai saattohoidoksi. Näistä hoitojaksoista 288 (80 \%) päättyi potilaan kuolemaan.

Kuolemaan päättyneiden hoitojaksojen potilaat olivat keskimäärin kolme vuotta vanhempia kuin potilaat, joiden hoitojakso ei päättynyt kuolemaan. Hoitojaksolla kuolleista potilaista 44 prosenttia oli saapunut PTH-sairaalaan jatkohoitoon erikoissairaanhoidon osastojaksolta. Kuolemaan päättymättömillä hoitojaksoilla erikoissairaanhoidon osastojaksolta tulleiden osuus oli puolet pienempi (22\%). Kuolemaan päättyneet hoitojaksot olivat keskimäärin 2,6 vuorokautta pidempiä kuin muut PTHsairaaloiden hoitojaksot.

\section{Kuolemaan päättyneet hoitojaksot}

Kuolemaan päättyneiden hoitojaksojen potilailla yleisin päädiagnoosi ja hoitojakson syy oli syöpäsairaus (30 \%). Lähes yhtä yleisiä olivat verenkiertoelinten sairaudet (29\%). Kolmanneksi yleisimpiä olivat hengityselinten sairau$\operatorname{det}(18 \%)$, joista puolet oli keuhkokuumeita. Muistisairaudet olivat harvoin (3\%) päädiag- 
Taulukko 1. Lyhytaikaiset hoitojaksot perusterveydenhuollon sairaaloissa Kuopion yliopistollisen sairaalan erityisvastuvalueella, jaoteltuina kuolemaan ja ei kuolemaan päättyneisiin hoitojaksoihin.

\begin{tabular}{|lcr|}
\hline Muuttuja (95\% luottamusväli) & Kuolleet $n=625$ & Ei kuolleet $n=13244$ \\
lkä, keskiarvo, vuosia & $80,7(77,6-83,8)$ & $76,7(76,0-77,4)$ \\
lkäryhmittäin, \% & & \\
$<65$ & $8(6-10)$ & $16(15-17)$ \\
$65-74$ & $16(13-19)$ & $17(16-18)$ \\
$75-84$ & $32(28-35)$ & $33(32-34)$ \\
$\geq 85$ & $44(40-48)$ & $33(32-34)$ \\
Sukupuoli nainen, \% & $49(45-53)$ & $55(54-56)$ \\
Hoitojakson kesto keskiarvo/mediaani, vrk & $8,6 / 6,0(6,4-10,8)$ & $6,0 / 4,0(5,6-6,4)$ \\
Mistä tuli osastolle? \% & & \\
Erikoissairaanhoidon jakson jälkeen & $44(40-48)$ & $22(21-23)$ \\
Oman terveyskeskuksen kautta & $35(31-39)$ & $44(43-45)$ \\
Ympärivuorokautisen päivystysjärjestelmän kautta & $21(18-24)$ & $32(31-33)$ \\
Tieto puuttuu & $1(0,2-1,8)$ & $2(1,7-2,2)$ \\
\hline
\end{tabular}

noosina potilaan kuolemaan päättyneillä hoitojaksoilla.

Kuoleman läheisyys tiedostettiin vajaassa puolessa $(46 \%, \mathrm{n}=288)$ potilaan kuolemaan päättyneistä hoitojaksoista. Virallinen saattohoitopäätös oli tehty kolmannekselle (33\%, $\mathrm{n}=209$ ) potilaista ja elämän loppuvaiheen hoidoksi ilman saattohoitopäätöstä oli määritelty 13 prosenttia $(\mathrm{n}=79)$ potilaan kuolemaan päättyneistä hoitojaksoista. Syöpäsairaudet olivat yleisin (52 \%) päädiagnoosien ryhmä saattohoidoksi tai elämän loppuvaiheen hoidoksi määritellyillä hoitojaksoilla, jotka päättyivät potilaan kuolemaan. Seuraavaksi yleisimpiä päädiagnoosien ryhmiä olivat verenkiertoelimistön sairaudet $(21 \%)$, hengityselinten sairaudet $(9 \%)$ ja muistisairaudet (4\%).

Hoidon kesto on esitetty kuviossa 1 . Kuolemaan päättyneiden hoitojaksojen potilaista 155 (25 \%) oli PTH-sairaalassa enintään kaksi vuorokautta ennen kuolemaansa. Heistä 38 prosenttia tuli PTH-sairaalaan oman terveyskeskuksen kautta. Erikoissairaanhoidon osastojaksolta jatkohoitoon tulleita oli myös reilu kolmannes (36 \%), ja neljännes (24\%) tuli ympäri vuorokauden toimivista päivystyksistä. Terveyskeskuksen tai päivystyksen kautta enintään kahden hoitovuorokauden jaksolle tulleis- ta potilaista 65 prosenttia tuli kotoa ja 35 prosenttia ympärivuorokautisesta hoiva-asumisesta. Kotoa tulleista potilaista 66 prosenttia sai säännöllistä kotihoitoa. Yleisimmät hoitojaksojen päädiagnoosit enintään kahden vuorokauden hoitojaksoilla olivat verenkiertoelimistön sairaudet (33\%), syöpäsairaudet (23\%) ja hengityselinten sairaudet (19\%). Enintään kaksi vuorokautta ennen kuolemaansa PTHsairaalaan saapuneista potilaista vajaalla puolella (47 \%) kuoleman läheisyys oli tiedostettu, saattohoitopäätös oli tehty 27 prosentille ja 20 prosentilla oli kyse muutoin määritellystä elämän loppuvaiheen hoidosta.

Vertailutiedoksi kerrotaan, että KYS ervaalueella menehtyi yhteensä 10000 henkilöä vuonna 2016. Sydän- ja verenkiertoelimistön sairauksiin menehtyi 39 prosenttia kaikista KYS erva-alueella kuolleista, mikä oli noin kolme prosenttiyksikköä enemmän kuin koko maassa. Seuraavaksi yleisimmät peruskuolemansyiden ryhmät KYS erva-alueella vuonna 2016 olivat syöpäsairaudet (21\%) ja muistisairaudet (17\%). Syöpäsairauksista yleisimpiä olivat keuhko- ja hengitysteiden syövät, haimasyöpä ja eturauhassyöpä. Hengityselinten sairaudet olivat peruskuolemansyinä 3 prosentilla (Tilastokeskus 2018b). 


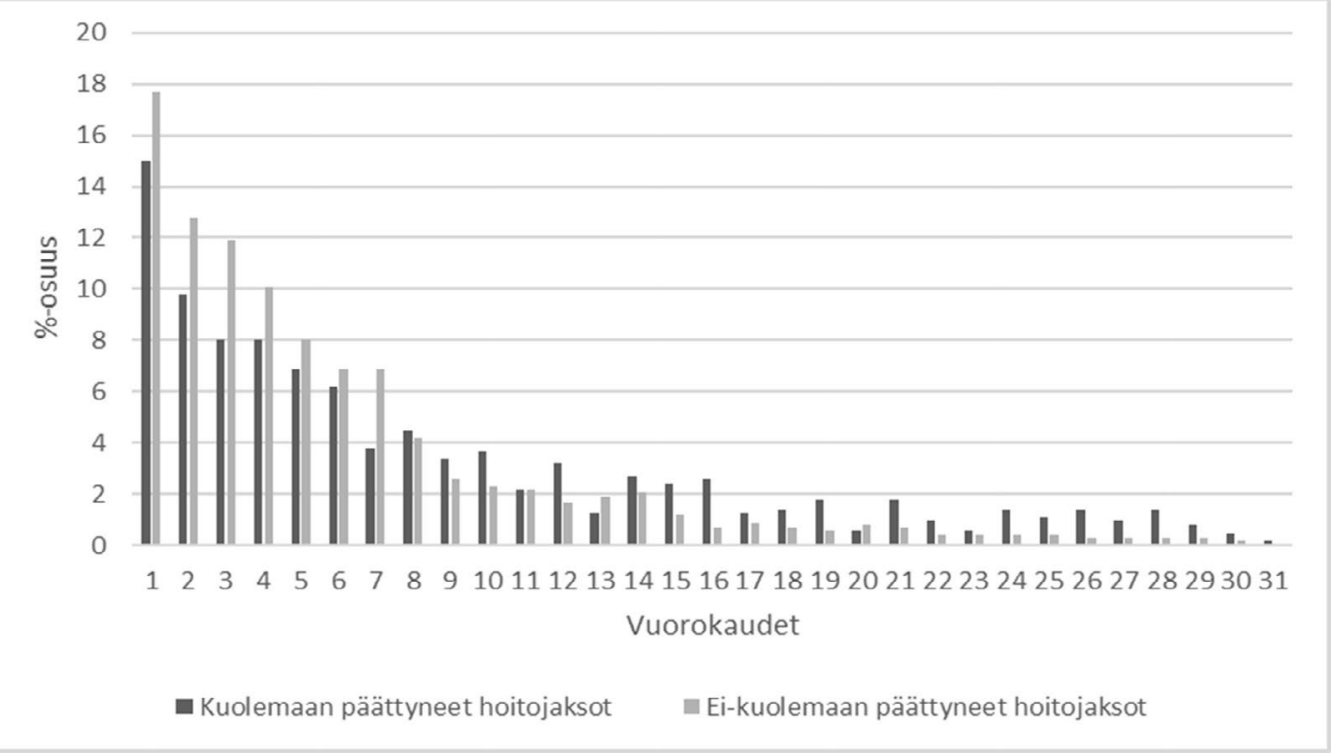

Kuvio 1. Lyhytaikaisten hoitojaksojen kesto päivinä Kuopion yliopistollisen sairaalan erityisvastuualueella, jaoteltuna kuolemaan päättyneisiin hoitojaksoibin ja ei-kuolemaan päättyneisiin hoitojaksoibin, \%.

\section{Pohdinta}

Tutkimme lyhytaikaisia, enintään 31 vuorokautta kestäneitä PTH-sairaaloiden hoitojaksoja KYS erva-alueella.Tämän osatutkimuksen huomion kohteena olivat potilaan kuolemaan päättyneet hoitojaksot. Kuoleman läheisyys tiedostettiin hieman alle puolessa potilaan kuolemaan päättyneistä hoitojaksoista. Syöpäsairaudet olivat yleisin hoidon syy. Myös linjaus elämän loppuvaiheen hoidosta tai saattohoidosta oli tehty yleisimmin syöpää sairastaville potilaille. Potilaan kuolemaan päättyneistä hoitojaksoista lähes puolet oli erikoissairaanhoidon osastojakson jälkeistä jatkohoitoa. Neljännes hoitojaksoista oli hyvin lyhyitä, enintään kahden vuorokauden mittaisia.

Yli puolessa (54\%) potilaan kuolemaan päättyneistä hoitojaksoista hoidon tarkoitusta ei ollut määritelty elämän loppuvaiheen hoidoksi tai saattohoidoksi. Pohdittavaksi jää, puuttuiko hoitolinjaus, vaikka kuoleman läheisyys tiedostettiin, vai tuliko kuolema kaikille osapuolille yllätyksenä. Jos kuoleman läheisyys tiedostettiin, syitä saattohoidon tai elämän loppuvaiheen hoidon linjausten puuttumiselle voi vain arvailla. Oliko suhtautuminen kuolemaan torjunnallista, eikö linjausten tekemiselle ollut tarpeeksi aikaa, resursseja tai osaamista, jäivätkö kuolevien tarpeet muun hoitamisen katveeseen? Tutkimuksemme PTH-sairaaloiden lyhytaikaisista hoitojaksoista valtaosa (96\%) ei päättynyt potilaan kuolemaan, vaikka suomalaisten kuolemista merkittävä osuus tapahtuu PTH-sairaaloissa (Forma ym. 2012).

Syöpää sairastavat mielletään ehkä yleisimmin saattohoitoa tarvitsevaksi potilasryhmäksi. Näin oli myös tutkimuksessamme. Useimmat kansansairautemme ovat kuolemaan johtavia pitkäaikaissairauksia. Niiden loppuvaihe pitäisi tunnistaa ja ottaa kuoleman läheisyys esille potilaan sekä hänen läheistensä kanssa. Kuitenkin esimerkiksi muistisairaus oli päädiagnoosina vain muutamalla prosentilla tutkimuksemme potilaista, joilla kuoleman läheisyys oli tiedostettu ja asiaan kuuluvat hoitolinjaukset tehty. Elämän loppuvaiheen hoidossa on kehitettävää myös muiden kuin syöpäsairauksien kohdalla. 
PTH-sairaalassa enintään 31 vuorokauden hoitojaksoilla kuolleiden potilaiden päädiagnoosit poikkesivat jonkin verran valtakunnallisista vuoden 2016 kuolinsyistä. Sekä omassa aineistossamme että valtakunnallisesti kaksi yleisintä diagnoosiryhmää olivat sydän- ja verenkiertoelinsairaudet sekä syöpäsairaudet. Eroavuutta ilmeni muistisairauksien ja hengityselinten sairauksien kohdalla. Tutkimuksessamme ei kerätty potilaiden kuolintodistusten tietoja, vaan hoitojaksoista kirjattiin päädiagnoosi, mikä useimmin ilmentää potilaan akuuteinta sairautta. Kuolemaan päättyneen hoitojakson päädiagnoosi ei siis välttämättä ole potilaan peruskuolinsyy. Valtakunnalliset kuolinsyytilastot taas laaditaan peruskuolinsyiden mukaan. Peruskuolinsyyksi nimetään voimakkaimmin, ja usein myös pitkäaikaisesti, potilaan toimintakykyä heikentänyt tila. Tutkimuksessamme hoitojakson päädiagnoosiksi merkitty keuhkokuume saattoi olla potilaan kuoleman kannalta välittömän kuolinsyyn tai kuolemaan myötävaikuttaneen syyn asemassa, mutta peruskuolinsyy saattoi olla pitkäaikaissairaus, kuten muistisairaus. Joka tapauksessa kirjallisuudessa on ennestään vain vähän tietoa PTH-sairaaloissa tapahtuneista kuolemista, vaikka suuri osa iäkkäistä suomalaisista kuolee terveyskeskusten osastoilla. Tätä puutetta tutkimuksemme osaltaan korjaa.

Aiemmin Aaltonen ja kumppanit (2010) ovat selvittäneet potilaiden siirtoja hoitopaikkojen välillä kuolemaa edeltävän kahden vuoden ajalta. PTH-sairaalassa kuolleista yli 90 prosenttia siirtyi hoitopaikasta toiseen kahden viimeisen elinvuoden aikana. Keskimäärin siirtymiä oli kuusi. Tutkimus ei kuitenkaan kerro viimeistä siirtymää ennen kuolemaa. Omassa tutkimuksessamme ilmeni, että lähes puolet PTH-sairaaloissa kuolleista potilaista tuli erikoissairaanhoidon osastojaksolta, kolmannes tuli suoraan terveyskeskuksesta ja viidennes keskitetystä päivystyksestä.

Kirjallisuudessa on esitetty, että PTH-sairaaloissa kuolleista potilaista noin puolet ehtii olla hoidettavana 2-3 viikkoa ennen kuole- maansa (Forma ym. 2012). Tutkimuksemme poikkeaa Forman ja kumppaneiden tutkimuksesta siinä, että tarkastelimme vain PTH-sairaaloiden lyhytaikaisia hoitojaksoja. Tutkimuksessamme suurin osa (69\%) kuolemista tapahtui alle 10 vuorokauden kuluessa PTHsairaalaan saapumisesta, ja 58 prosenttia potilaista oli PTH-sairaalassa enintään viikon.

Lyhyimmistä, enintään kaksi vuorokautta kestäneistä, hoitojaksoista reilu kolmannes alkoi potilassiirrolla erikoissairaanhoidon osastolta. Pohdittavaksi jää, miksi heikkokuntoisia kuolemaa lähestyviä potilaita siirrettiin sairaalasta toiseen. Siirrot hoitoyksiköstä toiseen ovat kuolevalle ja hänen läheisilleen rasite, joka vie aikaa ja tilaa itse kuoleman läheisyyden käsittelyltä (Gozalo ym. 2011). "Tarvetta erikoissairaanhoidolle ei ole" -perustelu lienee yksi selitys kuolemaa lähestyvän potilaan sairaalasiirrolle. Taustalla voi olla paine saada erikoissairaanhoidon hoitopaikka seuraavan potilaan käyttöön tai vaikeus arvioida kuoleman todellista läheisyyttä. Myös kotihoidosta potilaita siirtyi lyhyille hoitojaksoille PTH-sairaaloihin ennen kuolemaa. PTH-sairaalat toimivat kotihoidon tukiosastoina, jonne potilas voidaan tarvittaessa siirtää, mikäli kotihoidon resurssit eivät riitä turvaamaan kuolevan tarvitsemaa hoitoa. On myös mahdollista, että potilaat tarvitsivat sellaista oireiden lievitystä, jota kotona ei pystytty toteuttamaan.

\section{Tutkimuksen vahvuudet ja heikkoudet}

Tutkimuksemme edustaa hyvin yhden ervaalueen lyhytaikaista PTH-sairaalahoitoa. Toisaalta tuloksemme eivät välttämättä ole yleistettävissä valtakunnallisesti, sillä erikoissairaanhoidon ja perusterveydenhuollon työnjako voi vaihdella erva-alueittain ja sairaanhoitopiireittäin. PTH-sairaalatutkimuksen ensisijainen huomio ei kohdistunut kuolemaan päättyneisiin hoitojaksoihin. Tämän osatutkimuksen kannalta esimerkiksi kuolintodistuksiin kirjatut tiedot olisivat olleet käyttökelpoisia. Hoitojaksojen päädiagnoosit olivat kuitenkin käy- 
tettävissämme, samoin hoitavien lääkäreiden arviot hoidon tarkoituksesta. Tuloksiamme voidaan hyvällä syyllä pitää suuntaa antavina suomalaisessa terveydenhuoltojärjestelmässä.

Tekemämme 31 vuorokauden rajaus hoitojaksojen kestossa vaikuttaa myös tulosten yleistettävyyteen ja kuolemantapausten kuvauksen kattavuuteen. Suurin osa aineistomme hoitojaksoista oli alle 10 vuorokauden mittaisia, ja hoitojaksojen määrä väheni hoitovuorokausien lisääntyessä. Rajaus vaikutti myös tulosten vertailtavuuteen aiempiin tutkimuksiin. Toisaalta 31 vuorokauden rajaus mahdollisti sen, että tutkimuksessamme oli pääasiassa akuuteista hoidollisista syistä sairaalassa olevia potilaita, eivätkä aineistossa olleet yliedustettuina esimerkiksi hoiva-asumiseen pääsyä odottavat potilaat.

Aineisto kerättiin tutkimusta varten laaditulla lomakkeella, jonka täyttämiseen yksiköt saivat sekä kirjallisen että suullisen ohjeistuksen. Yksiköiden sitoutuminen aineiston keräämiseen oli hyvä: kaikki tutkimukseen mukaan lähteneet osastot palauttivat täytettyjä tutkimuslomakkeita koko tiedonkeruujaksolta. Valitettavasti tietoa siitä, täytettiinkö tutkimuslomake kaikilta hoitojaksoilta, ei ole, joten mahdollista katoa ja vastausprosenttia emme tiedä. Vaikka lomakkeen kysymykset olivat selkeitä ja varsin yksiselitteisiä, vastaajien keskuudessa on saattanut esiintyä toisistaan poikkeavia tulkintoja. Tutkimus ei aiheuttanut potilaille toimenpiteitä, ja oletuksenamme oli, ettei tutkimus vaikuttanut potilaiden hoitoon, vaan hoito toteutui tavanomaiseen tapaan.

\section{Kirjallisuus}

Aaltonen M, Forma L, Rissanen P, Raitanen J, Jylhä M. Transitions in health and social service system at the end of life. Eur J Ageing 2010;7(2):91-100. https://dx.doi.org/10.1007/s10433-010-0155-3

Blomgren J, Einiö E. Laitoshoidon vähenemisen yhteys ikääntyneiden muihin pitkäaikaishoivan palveluihin ja sairasvakuutuksen korvaaminen lääk-

\section{Johtopäätökset}

Tutkimuksen tulokset antavat ajankohtaista tietoa PTH-sairaaloissa kuolleiden potilaiden hoitojaksoista. Saattohoidon ja elämän loppuvaiheen hoidon osalta tuloksemme tukevat aiempaa käsitystä siitä, että syöpäsairauksissa saattohoidon tarve on paremmin tiedostettua verrattuna muihin kuolemaan johtaviin sairauksiin. Perusterveydenhuollossa tulee olla valmiudet toteuttaa perustason palliatiivista hoitoa ja saattohoitoa kaikille potilasryhmille. Myös sairaalasiirrot juuri ennen kuolemaa kiinnittivät huomiota. Turhia siirtoja on syytä välttää ja taata näin potilaalle kuolinrauha sekä läheisille mahdollisuus olla kuolevan ihmisen rinnalla. Kuoleman ja kuolevien hoidon tutkiminen on tärkeä osa palliatiivisen ja saattohoidon kehittämistä. Tutkimme lyhytaikaisessa PTH-sairaalahoidossa tapahtuneita kuolemia yhdellä erva-alueella. Jatkossa valtakunnallinen tutkimus ilman hoidon keston rajausta puoltaa paikkaansa.

\section{Yhteydenotto:}

\section{Alisa Piikki, LK}

Kansanterveystieteen ja kliinisen

ravitsemustieteen yksikkö,

Lääketieteen laitos

Itä-Suomen yliopisto

alisapii@student.uef.fi

g keiden kustannuksiin vuosina 2000-2013. Yhteiskuntapolitiikka 2015;80(4):334-48.

Forma L, Aaltonen M, Pulkki J, Raitanen J, Rissanen $\mathrm{P}$, Seinelä L ym. Pitkäaikaishoito viimeisenä elinvuotena - Vertailussa suuret kaupungit ja muu Suomi 2002-2013. Suomen lääkärilehti 2018;73(38):2086-98. 
Forma L, Jylhä M, Aaltonen M, Raitanen J, Rissanen P. Vanhuuden viimeiset vuodet. Kaks - Kunnallisalan kehittämissäätiö, 2012. Internet: https:// kaks.fi/wp-content/uploads/2012/11/Forma_ Jylh\%C3\%A4_Aaltonen.pdf (viitattu 30.5.2020).

Gozalo P, Teno J, Mitchell S, Skinner J, Bynum J, Tyler D, Vincent M. End-of-life transitions among nursing home residents with cognitive issues. N Engl J Med 2011;365(13):1212-21. https://doi.org/10.1056/nejmsa1100347

Käypä hoito -suositus/Palliatiivinen hoito ja saattohoito. Suomalaisen Lääkäriseura Duodecimin ja Suomen Palliatiivisen Lääketieteen yhdistyksen asettama työryhmä. Helsinki: Suomalainen Lääkäriseura Duodecim, 2018. Internet: www.käypähoito.fi (viitattu 18.11.2019).

Käypä hoito -suositus/Sydämen vajaatoiminta. Suomalaisen Lääkäriseura Duodecimin ja Suomen Kardiologisen seuran asettama työryhmä. Helsinki: Suomalainen Lääkäriseura Duodecim, 2017. Internet: www.käypähoito.fi (viitattu 17.7.2018).

Lunney JR, Lynn J, Hogan C. Profiles of older medicare decedents. J Am Geriatr Soc 2002;50(6): 1108-12.

https://doi.org/10.1046/ j.1532-5415.2002.50268.x

Mikkola M, Rintanen H, Nuorteva L, Kovasin M, Erhola M. Valtakunnallinen sosiaali- ja terveydenhuollon laitospaikkaselvitys. Terveyden ja hyvinvoinnin laitos, 2015.

Saari H, Lönnroos E, Mäntyselkä P, Ryynänen OP, Kokko S. Mitä on perusterveydenhuollon lyhytaikainen sairaalahoito? Suomen lääkärilehti 2019;74(44):2506-25.
Saarivaara S, Lämsä R, Seppälä U. Kuolema vuodeosastolla - kuolevan potilaan hyvän hoidon edellytykset. Gerontologia 2018;32(1)4-20.

Saarto T ja asiantuntijatyöryhmä. Palliatiivisen hoidon ja saattohoidon järjestäminen. Työryhmän suositus osaamis- ja laatukriteereistä sosiaali- ja terveydenhuollon palvelujärjestelmälle. Sosiaali- ja terveysministerion raportteja ja muistioita 2017:44. Internet: https://julkaisut.valtioneuvosto.fi/bitstream/handle/10024/160392/Palliatiivisen\%20hoidon\%20ja\%20saattohoidon\%20 j\%c3\%a4rjest\%c3\%a4minen.pdf?sequence=1\&isAllowed =y (viitattu 30.5.2020).

Saukkonen SM, Vaurio S. Perusterveydenhuollon vuodeosastohoito vuosina 2015-2016. THL - tilastoraportti 8/2017. Internet:

https://www.julkari.fi/bitstream/handle/10024/134563/Tr13_2017.pdf?sequence $=1 \&$ isAllowed $=y$ (viitattu 30.5.2020).

Tilastokeskus. Kuolleet muuttujina vuosi, sukupuoli ja tiedot. Tilastokeskuksen PX-Web tietokannat. 2018a. Internet:

https://pxnet2.stat.fi/PXWeb/pxweb/fi/StatFin/ (viitattu 30.5.2020).

Tilastokeskus. Kuolleet muuttujina maakunta, peruskuolemansyy (54-luokkainen luokitus) ja vuosi. Tilastokeskuksen PX-Web tietokannat. 2018b. Internet: https://pxnet2.stat.fi/PXWeb/pxweb/fi/StatFin/ (viitattu 30.5.2020).

Tilvis R, Pitkälä K, Strandberg K, Sulkava R, Viitanen M. Geriatria. Duodecim, 2016. 